\title{
Practice parameter: The care of the patient with amyotrophic lateral sclerosis (an evidence-based review)
}

\section{Report of the Quality Standards Subcommittee of the American Academy of Neurology}

\author{
R.G. Miller, MD; J.A. Rosenberg, MD; D.F. Gelinas, MD; H. Mitsumoto, MD; D. Newman, MD; \\ R. Sufit, MD; G.D. Borasio, MD; W.G. Bradley, DM, FRCP; M.B. Bromberg, MD, PhD; B.R. Brooks, MD; \\ E.J. Kasarskis, MD, PhD; T.L. Munsat, MD; E.A. Oppenheimer, MD; \\ and the ALS Practice Parameters Task Force
}

Mission statement. The Quality Standards Subcommittee (QSS) of the American Academy of Neurology (AAN) is charged with developing practice parameters for physicians. This evidence-based review addresses some of the major management is sues in patients with ALS, and highlights the many areas in which more research is needed.

Justification. ALS is a progressive, degenerative motor neuron disease of unknown cause. Muscle atrophy and spasticity in limb and bulbar muscles result in weakness and loss of ambulation, oropharyngeal dysfunction, weight loss, and ultimately respiratory failure. Although advances in understanding the pathophysiology of ALS have stimulated the development of new drug therapies, ${ }^{1}$ the mainstay of treatment for ALS patients remains symptomatic management.

The practice parameters presented here comprise the first recommendations for the management of ALS based on a prescribed review and analysis of the peer-reviewed literature. These practice parameters were developed to improve the care and the quality of life of people with ALS by providing a rational basis for managing the disease.

Description of the process. A multidisciplinary task force, all with extensive ALS experience, included 19 physicians, 3 patients with ALS, 1 gas- troenterologist, 1 pulmonologist, 1 occupational therapist whose mother has ALS, and 1 nurse. In addition, consultants with expertise on ethics, practice parameter development, and medical library research participated in the process. The task force agreed to investigate five areas: 1) informing the patient and the family about the diagnosis and prognosis (also called "breaking the news") of ALS; 2) symptomatic treatment; 3 ) nutrition, and decisions about percutaneous endoscopic gastroscopy (PEG); 4) respiratory insufficiency and mechanical ventilation; and 5) advance directives and palliative care. To help achieve this goal, they developed several guiding principles or attributes of care:

\section{Principles of ALS management}

1. High priority should be placed on patient selfdetermination or autonomy as an underlying assumption in the therapeutic relationship. Delivery of both information and care must take into consideration the cultural and psychosocial context of the patient and the family.

2. Patients and families need information that is timed appropriately for decision making, and delivered well in advance of major management crossroads, especially for respiratory care. Moreover, decision making is a dynamic process that

*The investigators and institutions of the ALS Practice Parameters Task Force are listed in the Appendix on page 1320.

From the American Academy of Neurology, St. Paul, MN.

Approved by the AAN Quality Standards Subcommittee October 17, 1998. Approved by the Practice Committee January 23, 1999. Approved by the Executive Board of the AAN February 27, 1999.

Supported by the following with unrestricted educational grant support: The Essey Family Foundation, The Forbes Norris ALS Center Foundation, Rhone-Poulenc Rorer, Cephalon, and Amgen.

Received November 3, 1998. Accepted in final form January 2, 1999

Address correspondence and reprint requests to the American Academy of Neurology, 1080 Montreal Ave., St. Paul, MN 55116. 
may be subject to change as the disease becomes more severe.

3. The physician, in conjunction with other health care professionals, should address the full continuum of care for the patient with ALS, and nurture the therapeutic relationship from diagnosis through palliative care for the terminal phase of the disease.

4. Discussions regarding advance directives should be introduced by the physician and reevaluated at intervals of no more than 6 months. Similarly, helping patients understand the issues to be faced in the terminal phase of the disease must be accomplished in a timely and empathic fashion.

Within each of the areas of study, the task force developed a list of clinical questions faced by physicians caring for the ALS patient (table 1).

We searched OVID MEDLINE (1966 to date), OVID Excerpta Medica (EMBASE; 1974 to date), Cumulative Index to Nursing and Allied Health Literature (CINAHL; 1982 to date), OVID Current Contents (weeks 27 to 46, 1997), OVID BIOETHICSLINE (1973 to date), and OVID International Pharmaceutical Abstracts (IPAB; 1970 to date). The search included studies on humans only and all languages. In the first search, ALS, Lou Gehrig's disease, and motor neuron disease were searched for relevant subtopics. The second search on respiratory issues included neuromuscular diseases such as Duchenne muscular dystrophy, postpoliomyelitis, and spinal muscular atrophy. A third search regarding relating the diagnosis, palliative care, and advance directives included all neurologic diseases as well as AIDS and cancer.

The search yielded approximately 5,350 references with abstracts. After reviewing these abstracts, 750 articles containing the highest level of evidence were obtained (symptomatic management subcommittee reviewed 150 papers; palliative care, 190; nutrition, 230; and respiratory, 180). The strength of evidence in each paper was ranked using the definitions in table 2. Based on the strength of evidence, management recommendations were developed as guidelines or options using the definitions shown in table 3 . Evidence tables containing the extracted data are placed in a registry (National Auxiliary Publications Service [NAPS]: see Note at end of article) and are available on request. Position statements or guidelines from national societies on issues such as communicating the diagnosis, advance directives, and respecting patient autonomy were included as broad expert opinion, which in some cases was elevated to guideline status. However, evidence of therapeutic intervention from diseases other than ALS was downgraded to class III. Invasive therapy for symptom management (e.g., surgery or irradiation for sialorrhea) was not recommended unless there was evidence from ALS.
Table 1 Clinical questions addressed in ALS treatment recommendations

\begin{tabular}{|c|c|}
\hline Subcommittee & Clinical question \\
\hline Breaking the news & $\begin{array}{l}\text { How should a physician tell } \\
\text { patients that they have ALS? }\end{array}$ \\
\hline \multirow[t]{3}{*}{ Symptom management } & $\begin{array}{l}\text { What pharmacologic interventions } \\
\text { reduce sialorrhea? }\end{array}$ \\
\hline & $\begin{array}{l}\text { What nonpharmacologic treatment } \\
\text { options reduce sialorrhea? }\end{array}$ \\
\hline & $\begin{array}{l}\text { What pharmacologic measures } \\
\text { reduce pseudobulbar affect? }\end{array}$ \\
\hline \multirow[t]{10}{*}{ Nutrition management } & When is PEG indicated in ALS? \\
\hline & $\begin{array}{l}\text { What is the best way to detect } \\
\text { dysphagia in ALS? }\end{array}$ \\
\hline & $\begin{array}{l}\text { What is the risk of PEG placement } \\
\text { in patients with ALS? }\end{array}$ \\
\hline & $\begin{array}{l}\text { What is the effect of PEG in } \\
\text { preventing aspiration and } \\
\text { aspiration pneumonia? }\end{array}$ \\
\hline & $\begin{array}{l}\text { What is the efficacy of PEG in } \\
\text { prolonging survival? }\end{array}$ \\
\hline & $\begin{array}{l}\text { What are the early indications of } \\
\text { respiratory insufficiency? }\end{array}$ \\
\hline & $\begin{array}{l}\text { Does noninvasive ventilation } \\
\text { improve respiratory function or } \\
\text { increase survival? }\end{array}$ \\
\hline & $\begin{array}{l}\text { Does experience with noninvasive } \\
\text { ventilation aid decision making } \\
\text { regarding invasive ventilation? }\end{array}$ \\
\hline & $\begin{array}{l}\text { How do invasive and noninvasive } \\
\text { ventilation impact quality of life? }\end{array}$ \\
\hline & $\begin{array}{l}\text { What is the optimal method of } \\
\text { withdrawing both noninvasive } \\
\text { and invasive ventilation from } \\
\text { patients with ALS? }\end{array}$ \\
\hline \multirow[t]{4}{*}{ Palliative care } & $\begin{array}{l}\text { Is pain common in the terminal } \\
\text { phase of ALS? }\end{array}$ \\
\hline & $\begin{array}{l}\text { Can terminal dyspnea be relieved } \\
\text { by therapeutic intervention? }\end{array}$ \\
\hline & $\begin{array}{c}\text { Does hospice care improve quality } \\
\text { of life in the terminal phase? }\end{array}$ \\
\hline & $\begin{array}{l}\text { Do advance directives improve } \\
\text { quality of life in the terminal } \\
\text { phase of ALS? }\end{array}$ \\
\hline
\end{tabular}

PEG = percutaneous endoscopic gastroscopy.

Breaking the news. The diagnosis should be established according to well-accepted criteria. ${ }^{2}$ Telling the patient and the family that the diagnosis is ALS is a daunting task for the physician. If not performed appropriately, the effect can be devastating, leaving the patient with a sense of abandonment and destroying the patient-physician relationship. ${ }^{3}$ Studies of other fatal illnesses ${ }^{4-12}$ clearly demonstrated the advantages of utilizing specific techniques (table 4).

Recommendations. The following recommendations for communicating the diagnosis are based on 
Table 2 Definitions of classification of evidence

\begin{tabular}{cc}
\hline Class & Definition \\
\hline I $\quad \begin{array}{c}\text { Evidence provided by one or more well-designed, } \\
\text { randomized, controlled clinical trials }\end{array}$ \\
II $\quad \begin{array}{c}\text { Evidence provided by one or more well-designed, } \\
\text { observational clinical studies with concurrent controls } \\
\text { (e.g., case control and cohort studies) }\end{array}$ \\
III $\quad \begin{array}{c}\text { Evidence provided by expert opinion, case series, case } \\
\text { reports, and studies with historical controls }\end{array}$ \\
\hline
\end{tabular}

the literature review and broad expert consensus (position statements, etc.):

1. The physician should give the diagnosis to the patient and discuss its implications. Respect the cultural and social background of the patient in the communication process by asking whether the patient wishes to receive information or prefers that the information be communicated to a family member. (Guideline)

2. The diagnosis should always be given in person and never by telephone. (Guideline)

3. Provide printed materials about the disease and about support and advocacy organizations (Guideline), and a letter or audiotape summarizing what the physician has discussed. (Option)

4. Avoid the following: withholding the diagnosis providing insufficient information, delivering in formation callously, or taking away or not proyiding hope. (Guideline)

Research recommendations. Surveys or con trolled studies are needed in ALS to 1) assess patient and caregiver perceptions of each step in breaking the news to help improve the process, 2) determine whether current recommendations about breaking the news have an effect on outcomes (with focus on adequacy of patient coping strategies), 3) study the impact of culture and social environment on disclosure methods, and 4) include disclosure techniques in medical curricula and to evaluate their implementation.

Table 3 Classification of management recommendations

\begin{tabular}{ll}
\hline Classification & \multicolumn{1}{c}{ Definition } \\
\hline Standard & $\begin{array}{c}\text { A principle for patient management that reflects a } \\
\text { high degree of certainty based on class I } \\
\text { evidence, or very strong evidence from class II } \\
\text { studies when circumstances preclude randomized } \\
\text { trials }\end{array}$ \\
Guideline & $\begin{array}{l}\text { Recommendations for patient management } \\
\text { reflecting moderate clinical certainty (usually } \\
\text { class II evidence or strong consensus of class III } \\
\text { evidence) }\end{array}$ \\
& A strategy for patient management for which the \\
Option & is some conflicting evidence or opinion
\end{tabular}

Table 4 How should a physician tell patients that they have ALS (adapted from Ptacek and Eberhardt ${ }^{11}$ )

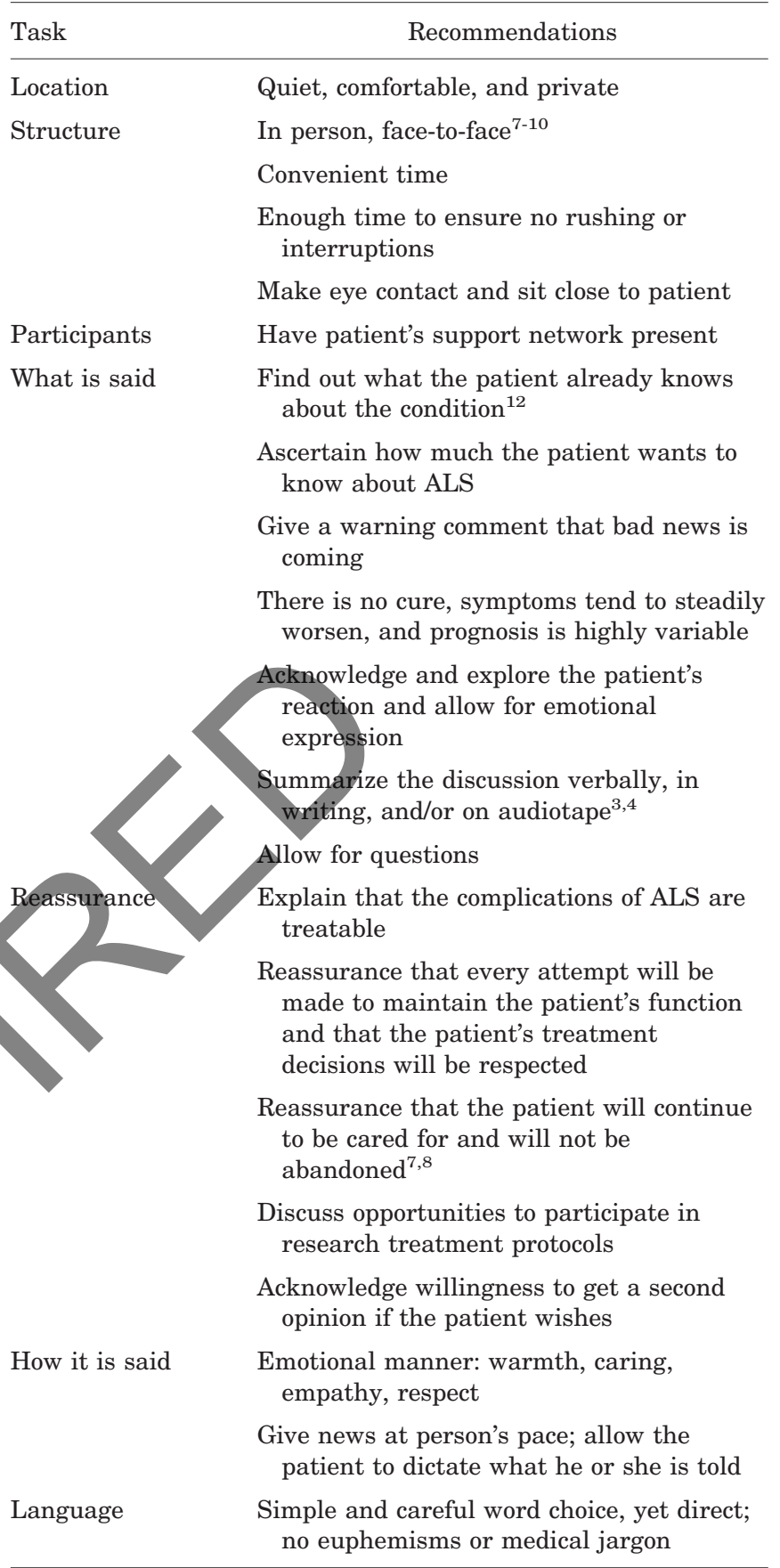

Symptom management (sialorrhea and pseudobulbar affect). The goal of symptom management is to improve the quality of life of the patient, family, and healthcare provider. Prominent symptoms include sialorrhea, pseudobulbar affect, speech impairment, sleep disorders and fatigue, depression, difficulties with activities of daily living, and ambulation. This section focuses on two particularly bothersome but treatable problems-sialorrhea and pseudobulbar affect-whereas other symptoms will be addressed in future documents.

Sialorrhea. Sialorrhea is important to the patient because it causes significant social stress. The 
physician must distinguish between sialorrhea and thick mucus production because treatment of these symptoms differs. Saliva production is actually decreased in patients with ALS. ${ }^{13,14}$ Thus, poor handling of saliva appears to be the major cause of sialorrhea in ALS and in other disorders such as cerebral palsy, mental retardation, developmental disability, Down syndrome, and oropharyngeal carcinoma. In these patients sialorrhea has been managed by attempting to decrease saliva production, improve handling of secretions, or divert and remove saliva. Because there is scant evidence in ALS, treatment of sialorrhea in other neurologic conditions was included in the analysis.

What pharmacologic interventions reduce sialorrhea? Two reports supported the use of glycopyrrolate (Robinul) for control of sialorrhea in patients with cerebral palsy or developmental disabilities..$^{15,16}$ Amitriptyline (Elavil) has been used widely in ALS but not studied in controlled trials. Decreased drooling in patients with cerebral palsy was also reported with benztropine (Cogentin), ${ }^{17}$ trihexyphenidyl hydrochloride (Artane), ${ }^{18}$ and transdermal hyoscine (Scopolamine).19,20 Transdermal hyoscine decreased drooling in developmentally delayed children, patients with mental retardation, and patients with oropharyngeal carcinoma. ${ }^{19,21}$ Atropine reduced sialorrhea in a crossover study of a patient with closed head injury. ${ }^{22}$ For thick mucus production associated. with sialorrhea, the addition of a beta blocker, such as propranolol (Inderal) or metoprolol (Toprol), appeared to confer clinical benefit for patients with ALS in an uncontrolled trial. ${ }^{23}$

What nonpharmacologic treatments reduce sialorrhea? Suction machines are widely used for symptom control, although we found no evidence supporting their value in ALS. Both manually assisted coughing techniques and mechanical insufflation-exsufflation (In-Exsufflator cough machine) were effective in extracting excess mucus from the airway. ${ }^{24}$ This device works by providing deep insufflation followed by an immediate decrease in pressure that creates a forced exsufflation. The InExsufflator was clinically effective in acutely ill ventilator-dependent, postpolio patients. ${ }^{25}$

Two additional approaches may be considered when medical treatments fail. External beam irradiation (3 to $30 \mathrm{~Gy}, 3$ to 10 fractions) to a single parotid gland may be effective in reducing sialorrhea, ${ }^{26}$ but it has not been evaluated in ALS. Surgical intervention has been tried in patients with ALS. ${ }^{14,27}$ However, no consistent evidence demonstrated efficacy, and there were reports of increased adverse events including death. ${ }^{27}$

Pseudobulbar affect. Pseudobulbar affect, or pathologic crying or laughing, is a troubling symptom for patients with ALS. The emotional lability is not a mood disorder, ${ }^{28}$ but an abnormal affective display $^{29}$ that occurs in as many as $50 \%$ of patients. ${ }^{30,31}$ The physician must be alert for pseudobulbar affect because patients and families often do not volunteer symptoms.

What pharmacologic measures reduce pseudobulbar affect? A randomized controlled trial in patients with MS supported the use of amitriptyline for pseudobulbar affect. ${ }^{32}$ A single study in a mixed population of patients including ALS reported satisfactory results with fluvoxamine (Luvox). ${ }^{33}$

\section{Recommendations. For sialorrhea:}

1. Treat sialorrhea with glycopyrrolate (figure 1), benztropine, transdermal hyoscine, atropine, trihexyphenidyl hydrochloride, or amitriptyline. (Option)

2. Treat thick mucus production associated with sialorrhea with propranolol or metoprolol. (Option)

3. Consider manually assisted coughing and mechanical insufflation-exsufflation for clearing secretions, especially during acute infection. (Option)

\section{For pseudobulbar affect (emotional lability):}

1. Treat pseudobulbar affect with amitriptyline. (Option)

2. Consider fluyoxamine as an alternate choice. (Option)

Research recommendations.

1. Conduct randomized controlled trials to study anticholinergic medications for sialorrhea in ALS.

2. Develop more efficient mechanical devices for handling saliva and thick mucus.

3. Examine the safety and efficacy of parotid irradiation and surgical procedures for sialorrhea in ALS.

4. Study selective serotonin reuptake inhibitors for pseudobulbar affect in ALS.

Nutrition. Patients with dysphagia are at risk for suboptimal caloric and fluid intake, ${ }^{34,35}$ and a worsening of muscle atrophy, weakness, and fatigue. Common symptoms include jaw weakness and fatigue, drooling, choking on fluid and food, and slow eating. Barium swallow may assist in developing strategies to maintain oral intake. The presence of laryngeal penetration on video fluoroscopy in the setting of dysphagia indicates a high risk for subsequent pneumonia. ${ }^{36,37}$ However, the variance among experienced speech pathologists in interpreting video fluoroscopy is large. ${ }^{38}$

As dysphagia progresses, PEG should be considered as an alternative or supplemental route for oral nutrition (figure 2). The immediate benefits are adequate nutritional intake, weight stabilization, and an alternate route for medication..$^{39,40}$ People with PEG can often continue to swallow some liquids and solids. Patients and families are generally positive regarding PEG, ${ }^{41-43}$ although the impact of PEG on quality of life in ALS has not been studied in detail. 


\section{Clinical complaint: drooling (sialorrhea)}

$\downarrow$

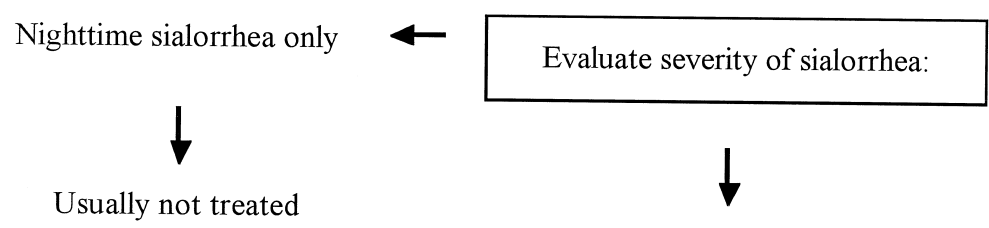

Daytime and nighttime sialorrhea

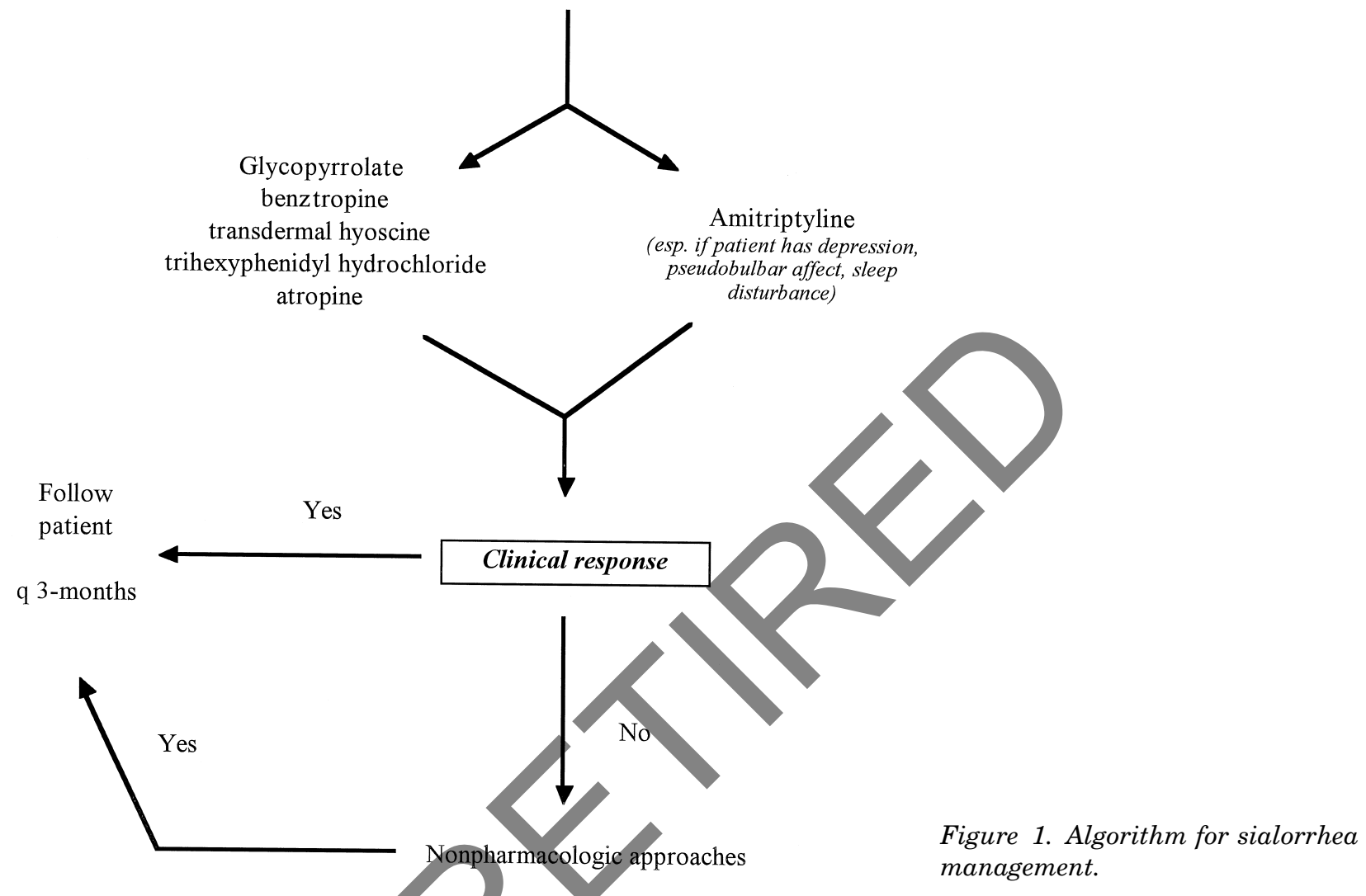

When is a PEG indicated in ALS? Initial management of dysphagia in patients with ALS includes modification of food and fluid consistency, and coaching by a speech pathologist. If this fails, evaluation for PEG tube placement is then warranted. ${ }^{43}$

In ALS, the recommendation for PEG should be made before the forced vital capacity (VC) falls to $50 \%$ of predicted (discussed later) and not in the preterminal phase. ${ }^{39,40}$ The decision is based on progression of dysphagia and family concern about feeding difficulties. Specifically, PEG is indicated when patients with ALS have symptomatic dysphagia with accelerated weight loss due to insufficient caloric intake, dehydration, or ending meals prematurely because of dysphagia or choking on food. ${ }^{39,40}$ The timing of PEG should be considered in the context of pulmonary status (discussed later).

What is the best way to detect dysphagia in $A L S$ ? A careful history should be obtained at each visit to identify symptomatic dysphagia. There is no single test to detect dysphagia in patients with ALS. Questions regarding the physical manipulation of food and fluid (e.g., frequency of choking, texture of foods that cause problems, drooling, duration of meals, fatigue while eating) are revealing. Although a barium swallow study may provide supportive evidence for dysphagia, the indication for PEG in ALS depends on the presence of inadequate oral intake and diminished quality of life due to choking rather than the result of a swallowing study. ${ }^{43-46}$

What is the risk of PEG placement in patients with $A L S$ ? The onset of dysphagia may coincide with the insidious development of respiratory insufficiency, which is the major determinant of survival. ${ }^{47,48} \mathrm{Be}-$ cause PEG tube insertion typically employs procedural sedation, knowledge of a patient's respiratory capacity and monitoring of oxygen saturation are essential. ${ }^{49}$ To minimize risks, evidence indicates that PEG should be placed before VC falls below $50 \%$ of predicted..$^{39,40}$

Complications of PEG placement include transient laryngeal spasm (7.2\%), localized infection (6.6\%), gastric hemorrhage (1 to $4 \%$ ), failure to place PEG 


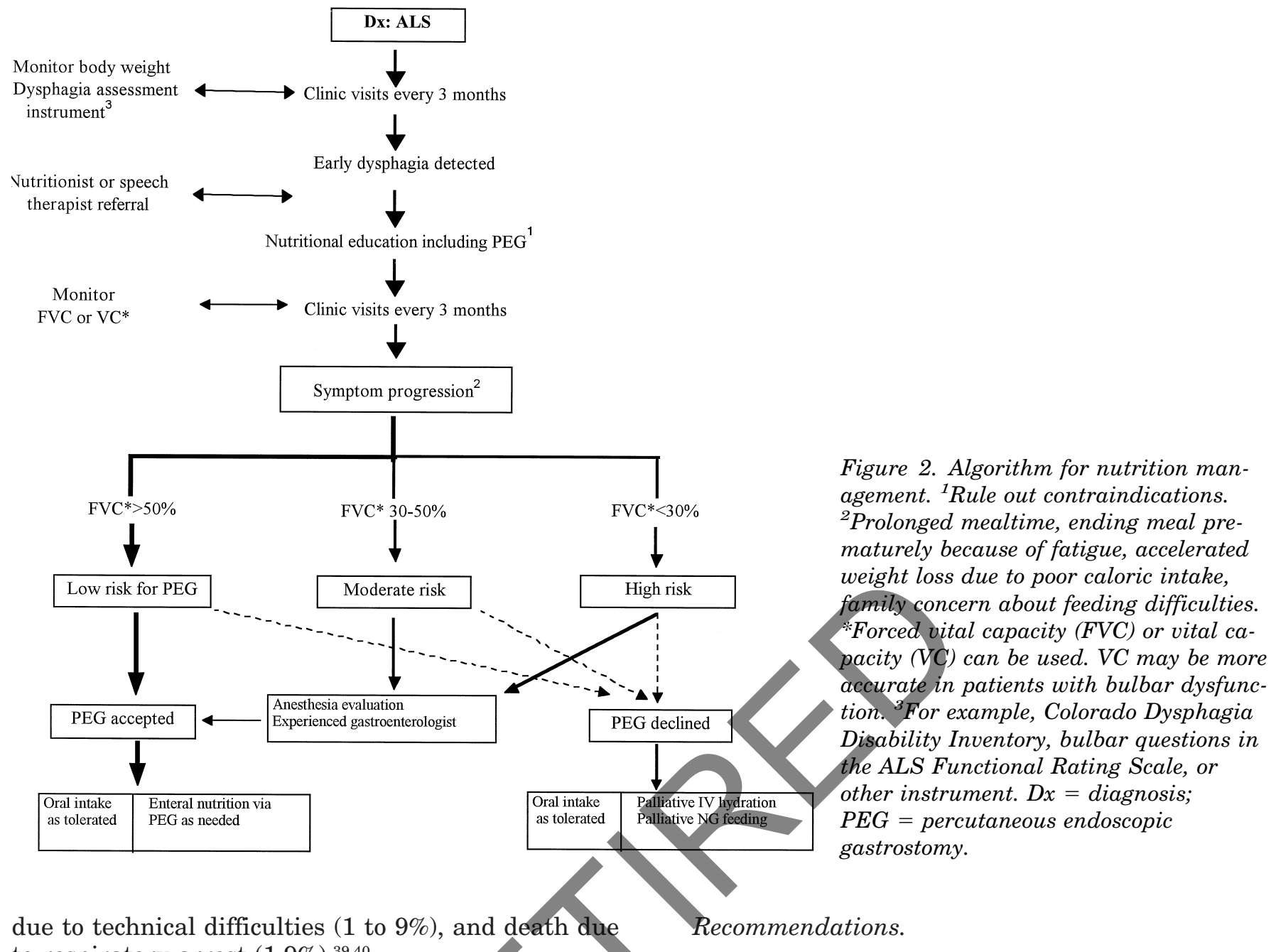

to respiratory arrest (1.9\%). ${ }^{39,40}$

What is the effect of PEG on preventing aspiration and aspiration pneumonia? PEG or percutaneous endoscopic jejunostomy does not prevent aspiration pneumonia. ${ }^{41,43,50-54}$ Therefore, prevention of aspiration pneumonia is not an indication for PEG. ${ }^{46}$ The major risk factors for post-PEG pneumonia include a pre-PEG history of aspiration pneumonia, presence of reflux esophagitis during endoscopy, and concurrent infection. ${ }^{51,52-56}$

Although not studied in ALS, a prokinetic agent (such as cisapride) to enhance gastric emptying may reduce the incidence of post-PEG aspiration. ${ }^{57}$ There is some evidence that recurrent aspiration pneumonia in aphonic patients with ALS may be treated with conservative laryngectomy or laryngeal diversion. ${ }^{58,59}$ The role of cricopharyngeal myotomy in the management of dysphagia in ALS is uncertain. ${ }^{45,60}$

What is the efficacy of PEG in prolonging survival? Two studies suggest that insertion of PEG may prolong survival. ${ }^{39,40}$ Patients with PEG lived an average of 1 to 4 months longer than patients who refused or who were deemed ineligible for PEG. ${ }^{39,40}$ The survival advantage was greatest in patients with a VC $>50 \%$ at time of PEG insertion. ${ }^{40}$ However, control subjects were not randomized and other factors that might influence survival (such as depression) were not evaluated systematically.
1. PEG is indicated for patients with ALS who have symptomatic dysphagia and should be considered soon after symptom onset. (Guideline)

2. For optimal safety and efficacy, PEG should be offered and placed when the patient's VC is more than $50 \%$ of predicted. (Guideline)

\section{Research recommendations.}

1. Establish the fluid and caloric requirements of patients with ALS at different stages of the illness.

2. Evaluate the incidence of utilizing PEG in ALS and of aspiration pneumonia after PEG.

3. Measure the effect of PEG intervention on survival and quality of life in ALS.

4. Study the decision-making process to understand which factors are important to patients.

5. Promote understanding of nutritional issues and standardize nutritional care to facilitate planning future clinical trials and meta-analyses of new drugs for ALS.

6. Evaluate the efficacy of conservative laryngectomy for recurrent aspiration pneumonia in aphonic patients.

7. Study the impact of advance directives on future PEG placement. 


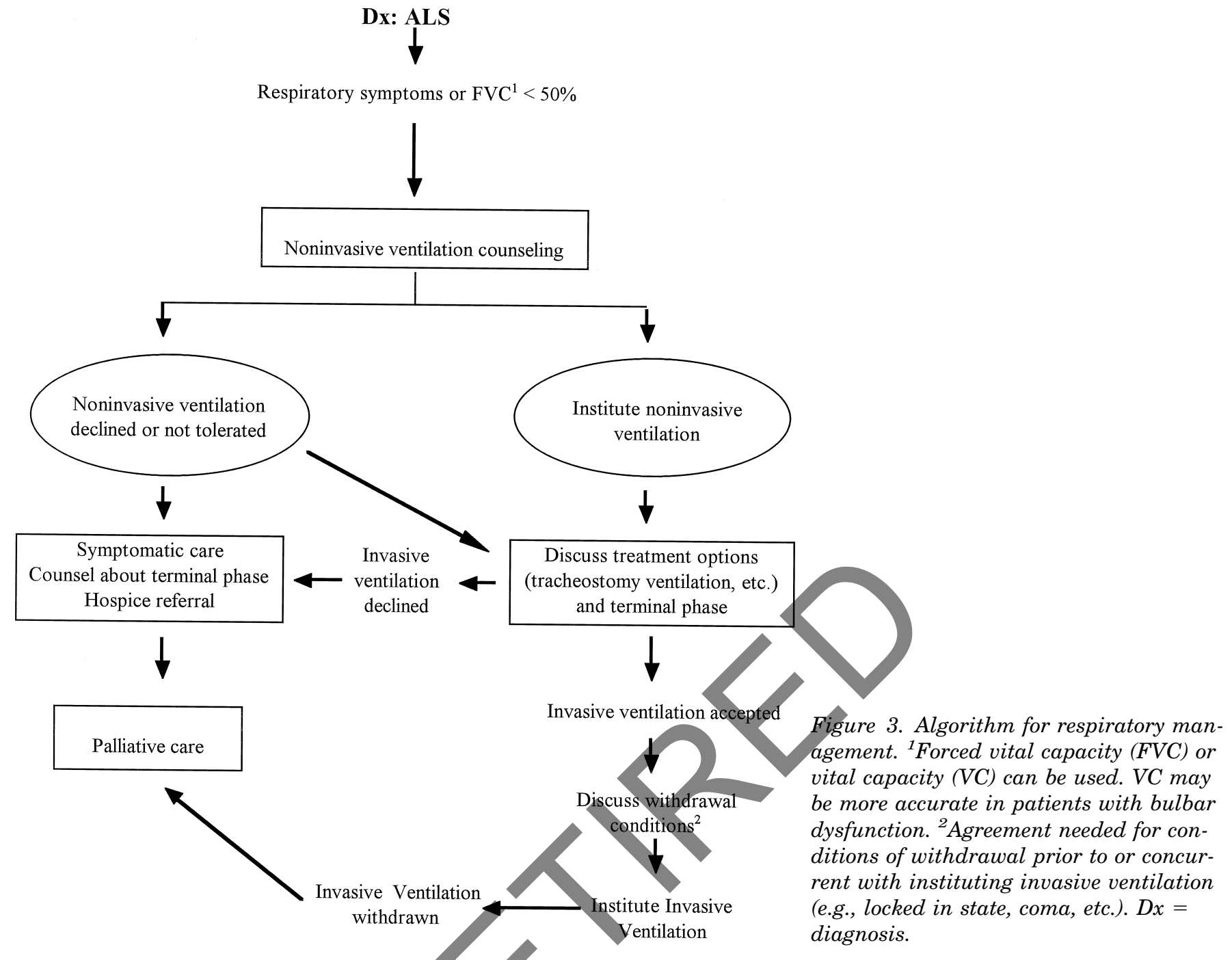

Respiratory management. Respiratory care presents the greatest challenge for the ALS patient and the clinician. Deciding when to initiate noninvasive mechanical ventilation is critical because of the risk of either sudden death or ventilator dependence without proper advance planning. ${ }^{61-64}$ An early understanding of the patient's preferences will help ensure careful and timely planning (figure 3 ).

What are the early indications of respiratory insufficiency? Early signs and symptoms of weakness of the respiratory muscles are subtle and easily overlooked if not sought specifically. ${ }^{65}$ Symptoms include dyspnea on exertion, supine dyspnea, marked fatigue, disturbed sleep (frequent nocturnal awakenings, excessive daytime sleepiness), and morning headaches. ${ }^{66,67}$ No evidence indicated the best test of detecting early signs of impending respiratory failure. Probably the most sensitive pulmonary measurement to detect early respiratory muscle weakness (respiratory insufficiency) is maximal inspiratory pressure, ${ }^{65}$ but no studies test its efficacy in detecting impending respiratory failure in ALS. Erect sitting VC, and possibly supine VC (to detect early diaphragmatic weakness), ${ }^{66}$ are useful in monitoring declining respiratory function. Thus, VC should be monitored in patients with ALS (although no published data indicated how frequently this should be performed). ${ }^{48,68}$ Nocturnal oximetry is useful in evaluating nocturnal hypoventilation. A full polysomnogram is an alternative test, but is not needed in most patients. ${ }^{66,69,70}$

A decrease in VC to $50 \%$ of predicted is often associated with respiratory symptoms. ${ }^{71,72}$ Even in the absence of symptoms, when the VC falls to this level, a number of planning steps must be taken (see figure 3). A VC less than $1 \mathrm{~L}$ (or less than 25 to $30 \%$ of predicted) indicates significant risk of impending respiratory failure or death. ${ }^{65}$ Bulbar impairment increases the risk of aspiration, ${ }^{64}$ and acute respiratory infection can precipitate sudden respiratory failure. ${ }^{64}$

Does noninvasive ventilation improve respiratory function or increase survival? Impaired ventilatory function, which is expected late in the course of ALS, occasionally occurs shortly after onset of symptoms. Patients, families, and physicians must then consider chronic ventilatory support. Patients and physicians often consider noninvasive ventilation more desirable than invasive ventilatory support with tracheostomy. Moreover, noninvasive ventilation offers direct clinical benefit to the patient. Several studies 
indicate that noninvasive ventilation improved the symptoms of hypoventilation, thereby improving quality of life ${ }^{63,73,74}$ and increasing survival of patients with ALS by several months. ${ }^{47,61,71,75}$ Invasive ventilation may increase survival more effectively but with a greater financial and care burden. ${ }^{71}$

Loss of bulbar muscle tone and difficulty clearing secretions reduce tolerance of noninvasive ventilation and may define the limit of noninvasive ventilation. ${ }^{61}$ Thus, patients with bulbar ALS may not tolerate noninvasive ventilation, and invasive ventilation should be considered..$^{72}$

Does experience with noninvasive ventilation aid decisions about invasive ventilation? When a patient can no longer tolerate noninvasive positivepressure ventilation or it fails to be effective, he or she has to choose between invasive ventilation with tracheostomy or palliative care (see figure 3). Limited evidence in patients with ALS suggests that some patients who experienced noninvasive ventilation decided against invasive ventilation when the noninvasive ventilation became ineffective. ${ }^{47,61,76,77}$ Moreover, some patients were on long-term invasive ventilation following emergency hospitalization in the absence of prior planning. ${ }^{71}$

The results of these studies suggest that previous experience with noninvasive ventilation may assist the patient and the family in deciding whether to use invasive ventilation, but this point is still not clear. $^{47,71,76,77}$

How do invasive and noninvasive ventilation impact quality of life? Patients with ALS who depend on long-term invasive or noninvasive ventilation, either full- or part-time, can lead meaningful lives, and few regret being on a ventilator. ${ }^{78-81}$ Collectively, these studies provide evidence that ventilatory support should be discussed with each patient with ALS well before the development of respiratory insufficiency symptoms..$^{78,79}$ Ventilator-dependent patients with ALS are not more depressed than patients with ALS who are not ventilator dependent. ${ }^{79}$ Additionally, because patient satisfaction is higher with noninvasive than invasive ventilation, noninvasive ventilation should be considered before tracheostomy. ${ }^{71}$ Patients on chronic invasive ventilation, and their families, bear a great financial, social, and emotional burden. ${ }^{80}$ The cost and possible benefit should be discussed openly and honestly with the patient and the family.

Caveat: Outside observers cannot assess accurately a patient's quality of life. In one study, medical personnel overestimated patient dissatisfaction significantly in every aspect measured, and they judged incorrectly that patients would be dissatisfied with life on a ventilator. ${ }^{82}$

What is the optimal method of withdrawing the patient from noninvasive and invasive ventilation? Legal and ethical precedents support the right of a mentally competent, informed patient to refuse or to discontinue any treatment, including life support and mechanical ventilation. Healthcare providers are required to respect such a request. ${ }^{26,76,77-88}$

As ALS progresses, most patients who select a ventilator become completely dependent on it. ${ }^{75} \mathrm{Un}$ fortunately the patient may ultimately become unable to communicate; therefore, it is critical to agree, prior to this point, which circumstances will trigger withdrawal of the ventilator. Although no rigorous comparative studies have investigated the optimal method for withdrawing mechanical ventilation, some retrospective studies, although not in patients with ALS, provided information on how to carry out this important procedure in a humane manner. ${ }^{88}$ The evidence in these studies was based on acute critical care experience with intubated patients in which the patient or family agreed to withdraw mechanical ventilation because there was no reasonable hope of recovery, and death was anticipated without ventilator support. From this experience, a stepwise approach is suggested. ${ }^{88}$ As defined by the principle of "double effect," the intention is to relieve suffering, not to hasten death, although death may be hastened as a consequence. ${ }^{89}$

When initiating ventilatory withdrawal, the primary goal is to maintain patient comfort. If utilizing supplemental oxygen, the first step is to discontinue supplemental oxygen and end positive expiratory pressure, followed by conversion to a T-piece and spontaneous breathing. ${ }^{88}$ Several reports provide timing and dosing details when withdrawing ventilatory support. ${ }^{85,90,91}$ At each step in the withdrawal process, patients may require pretreatment with a sedative-hypnotic (equivalent to $15 \mathrm{mg}$ per hour of IV diazepam [Valium]) and/or opioid (equivalent to $15 \mathrm{mg}$ per hour of IV morphine), raising the dose as necessary to relieve dyspnea and anxiety, even to the point of unconsciousness if necessary and requested. ${ }^{85,86}$ The use of a muscle-paralyzing agent during ventilator withdrawal was not supported in the literature. ${ }^{89}$

\section{Recommendations.}

1. Be vigilant for symptoms indicating hypoventilation. Serial measures of pulmonary function (especially VC) are recommended to guide management and to determine prognosis with the understanding that no single test can detect hypoventilation reliably. (Guideline)

2. Offer noninvasive ventilatory support as an effective initial therapy for symptomatic chronic hypoventilation and to prolong survival in patients with ALS. (Guideline)

3. When long-term survival is the goal, offer invasive ventilation and fully inform patient and family of burdens and benefits. (Guideline)

4. In accordance with the principle of patient autonomy, physicians should respect the right of the patient with ALS to refuse or withdraw any treatment, including mechanical ventilation. (Guideline)

5. When withdrawing ventilation, use adequate 
opiates and anxiolytics to relieve dyspnea and anxiety. (Guideline)

Bioethics statement: It is a strong consensus of both the ALS Task Force and the Quality Standards Subcommittee of the AAN that during withdrawal of ventilation, paralyzing drugs should not be used.

\section{Research recommendations.}

1. Study whether noninvasive ventilation improves quality of life and prolongs survival for patients with ALS.

2. Identify (a) whether early ventilatory support alters prognosis, (b) the optimal timing of ventilatory intervention, and (c) better noninvasive methods of ventilatory support.

3. Study methods of withdrawing both invasive and noninvasive respiratory support in ALS.

Palliative care. Ethical considerations. Shared decision making. The physician and the patient should share in decision making, understanding that cultural and religious values will have an impact on decisions. ${ }^{12}$ The physician should explain the risks and benefits of treatments at each visit in an unbiased way, and understand that the patient's choices could change as the disease progresses.

Goals of palliative care. As ALS progresses, the goal of patient care changes from maximizing function to providing effective and compassionate palliative care ${ }^{82-87}$ One approach to provide adequate relief from two of the most prevalent and unpleasant symptoms in the terminal phase-dyspnea and anxiety-is as follows ${ }^{112}$ :

1. Treatment of reversible causes of dyspnea if present (e.g., bronchospasm, pneumonia)

2. Treatment of intermittent dyspnea

a. Relief of anxiety ( 0.5 to $2 \mathrm{mg}$ lorazepam sublingually)

b. Inhaled opiates (e.g., $5 \mathrm{mg}$ morphine)

c. A total of 5 to $10 \mathrm{mg}$ IV midazolam (slowly) for severe dyspnea

3. Treatment of constant dyspnea

a. Opiates (e.g., morphine, start with $2.5 \mathrm{mg}$ IV/subcutaneously/transdermally, or oral equivalent every 4 hours

b. For severe dyspnea, continuous IV morphine infusion

c. Add 2.5 to $5 \mathrm{mg}$ diazepam or midazolam for nocturnal symptom control

d. For terminal restlessness, chlorpromazine (25 mg every 4 to 12 hours rectally or 12.5 mg every 4 to 12 hours IV)

4. Treatment of hypoxia with oxygen only

Continued communication with the paralyzed patient is often difficult and must be given high prior- ity. Psychological and spiritual guidance should also be offered.

Is pain common in the terminal phase of $A L S$ ? Although pain in ALS is not usual in the initial stages, ${ }^{92}$ between 40 and $73 \%$ of patients experience pain in later stages..$^{93-96}$ It may be caused by stiff joints, muscle cramps, or pressure on the skin or joints from immobility. In one series, $55 \%$ of patients responded to combinations of anti-inflammatory, antispasticity, and non-narcotic analgesic drugs. Among hospice patients with ALS, approximately $80 \%$ reported a good response to opioids. ${ }^{94}$ The World Health Organization (WHO) pain management recommendations for patients with cancer ${ }^{97}$ should be useful for pain management in patients with ALS. Strong evidence has documented the effectiveness of opioids for cancer pain, and two position papers from the AAN advocate opioids for treatment of pain in palliative care settings. ${ }^{83,86}$

Can dyspnea in terminal stages be relieved by therapeutic intervention? Dyspnea from respiratory muscle weakness occurs in approximately $50 \%$ of patients with AIS. ${ }^{94-96}$ Relief of dyspnea using opioids was rated as good by $81 \%$ of hospice patients with ALS. ${ }^{94}$ Opioids are adyocated for treating dyspnea in two AAN position papers regarding care of terminal neurologic patients. ${ }^{83,86}$ Although not studied in patients with ALS, oxygen was an effective treatment for dyspnea in hypoxemic cancer patients with restrictive lung disease ${ }^{98}$ Extreme caution is indicated when administering oxygen to nonterminal patients to avoid inducing hypoventilatory respiratory failure in hypercapnic patients. ${ }^{99}$

Patients who have attacks of dyspnea may benefit from calming techniques to reduce anxiety. Anxiety attacks due to dyspnea may be treated with shortacting anxiolytics, such as 0.5 to $2.0 \mathrm{mg}$ lorazepam sublingually. A prospective, uncontrolled study of cancer patients indicated that chlorpromazine (Thorazine) helped relieve symptoms of dyspnea. ${ }^{100}$ In an uncontrolled study of patients with cancer, acupuncture appeared to be helpful in treating dyspnea. ${ }^{101}$

Does hospice care improve quality of life in the terminal phase? Uncontrolled studies reported some benefit from hospice care in improving the quality of life of patients with ALS. ${ }^{94-96}$ In a randomized, controlled clinical trial in cancer patients, "satisfaction with interpersonal care," "involvement of care," and pain management were significantly better with hospice care than with conventional care. ${ }^{102}$ Using a measure of quality of death in cancer patients, hospice patients had better quality-of-death scores than conventional care patients. ${ }^{103}$ Uncontrolled studies suggest similar results from hospice care for patients with ALS. A retrospective analysis of hospice chart data showed that $94 \%$ of patients with motor neuron disease were judged to be "peaceful and settled" at death in hospice. ${ }^{94}$

Do advance directives improve quality of life for the patient in the terminal phase of ALS? We found no evidence that advance directives improve quality 
of life in any disease. In two studies, advance directives did not enhance physician-patient communication or decision making substantially for seriously ill cancer patients. ${ }^{104,105}$ Enhancing opportunities for more patient-physician communication and advance care planning also seemed inadequate to change established practices. ${ }^{106}$ However, physician education about advance directives can increase the frequency of their use significantly. ${ }^{107}$ Physicians are more likely to follow therapy-specific advance directives that are supported by a discussion with the patient than advance directives that are stated in generalities. ${ }^{108}$ Several studies reported that physicians and patients want to utilize advance directives. Patients want to initiate discussion about advance directives earlier than their physicians, but both patients and physicians believe that it should be the physician who initiates discussion. ${ }^{109,110}$ However, physicians often do not initiate discussion of advance directives. ${ }^{79}$ Importantly, patients with ALS have been shown to change their preference for life-sustaining measures (e.g., ventilators) over a 6 -month period. ${ }^{111}$

\section{Recommendations. For pain management:}

1. Utilize non-narcotic analgesics, anti-inflammatory drugs, and antispasticity agents for initial treatment of pain in patients with ALS. (Option)

2. Administer opioids liberally, following the WHO guidelines, when non-narcotic analgesics fail, (Guideline)

\section{ALS:}

For treating dyspnea in terminal stages of

1. Use opioids, alone or with supplemental oxygen, to treat dyspnea at rest in patients with ALS, despite the risk of respiratory depression with higher doses. (Guideline)

2. Consider chlorpromazine (Thorazine) and acupuncture as possible adjuncts. (Option)

\section{For hospice care:}

1. Consider referral to hospice in the terminal phase of ALS. (Option)

\section{For advance directives:}

1. Initiate a discussion of advance directives well in advance of the terminal phase and reevaluate at least every 6 months. (Option)

\section{Research recommendations.}

1. Study symptom prevalence and quality of life in the terminal phase of ALS.

2. Test the effectiveness of current treatments for palliative care.

3. Develop new therapeutic approaches for terminal ALS symptoms.

4. Study the effect of hospice care on quality of life for patients with ALS and families.

5. Compare hospice home care with hospice inpatient care.
6. Study the role and impact of advance directives on the dying process.

7. Include palliative care of the dying patient in medical education.

8. Examine the psychological impact of ALS on caregivers and health care providers.

\section{Acknowledgment}

The AAN QSS thanks Robert Miller, MD, and Jay Rosenberg, MD, for their service to the Academy as the Chair and Co-Chair of this practice parameter project, and the members of the multidisciplinary panel who provided their expertise, time, and insight into the careful development of this document.

We also thank the numerous individuals, AAN Sections, and organizations that reviewed drafts of the document, including the ALS Association, the Muscular Dystrophy Association, the AAN Ethics and Humanities Subcommittee, and the Motor Neuron Disease Research Steering Committee of the World Federation of Neurology.

American Academy of Neurology Quality Standards Subcommittee members: Gary Franklin, MD, Co-Chair; Catherine Zahn, MD, Co-Chair; Milton Alter, MD, PhD; Stephen Ashwal, MD; John Calverley, MD; Richard Dubinsky, MD; Jacqueline French, MD; Michael Greenberg, MD; Gary Gronseth, MD; Deborah Hirtz, MD; Robert Miller, MD; James Stevens, MD.

ALS Practice Parameters Task Force: members listed in Appendix.

This document has been endorsed by the American College of Chest Physicians.

Disclaimer

This statement is provided as an educational service of the Amercan Academy of Neurology. It is based on an assessment of current scientific and clinical information. It is not intended to include all possible proper methods of care for a particular neurologic problem or all legitimate criteria for choosing to use a speeific procedure. Neither is it intended to exclude any reasonable alternative methodologies. The AAN recognizes that specific patient care decisions are the prerogative of the patient and the physician caring for the patient, based on all of the circumstances involved.

\section{Appendix}

Chairman

Robert G. Miller, MD; California Pacific Medical Center; San Francisco, CA

Co-Chair

Jay H. Rosenberg, MD; Kaiser Permanente Medical Group; San Diego, CA

Nutrition work group

Hiroshi Mitsumoto, MD, Chair, Cleveland Clinic Foundation, $\mathrm{OH}$; Edward J. Kasarskis, MD, PhD, University of Kentucky, Lexington, KY; and Michael S. Verhille, MD, California Pacific

Medical Center, San Francisco, CA

Respiratory work group

Deborah Gelinas, MD, Chair, California Pacific Medical Center, San Francisco, CA; Mark B. Bromberg, MD, PhD, University of Utah School of Medicine, Salt Lake City, UT; and Edward A. Oppenheimer, MD, Southern California Permanente Medical

Group, Los Angeles, CA

\section{Symptomatic management work group}

Robert L. Sufit, MD, Chair, Northwestern University, Chicago, IL; Benjamin Rix Brooks, MD, University of Wisconsin Hospital \& Clinics, Madison, WI; Theodore L. Munsat, MD, Tufts University Medical Center, Newton, MA; and Steven P. Ringel, MD, University of Colorado Health Science Center, Denver, CO

Breaking the news and end-of-life issues work group Daniel S. Newman, MD, Chair, Henry Ford Hospital, Detroit, MI; Gian D. Borasio, MD, University of Munich, Germany; and

Walter G. Bradley, DM, FRCP, University of Miami School of Medicine, FL

Consultant to end-of-life work group

James L. Bernat, MD; Dartmouth Hitchcock Medical Center; Lebanon, $\mathrm{NH}$ 


\section{European participants}

Orla Hardiman, MD, MRCPI, Richmond Institute of Neurology, Beaumont Hospital, Dublin, Ireland; Pamela Shaw, MD, Royal Victoria Infirmary, Newcastle upon Tyne, UK; John H.J. Wokke, MD, Academisch Ziekenhuis Utrecht, The Netherlands; Vincenzo Silani, MD, University of Milan Medical School, Italy; Maria Sales-Luis, MD, Faculty of Medicine of Lisbon, Portugal; and A. Ludolph, MD, University of Ulm, Germany

\section{Epidemiology consultant}

Douglas C. McCrory, MD, MHSc; Duke University; Durham, NC

\section{Patient advocates}

Linda Centers, OTR/L, Eastern State Hospital, Lexington, KY; Dee Holden Norris, RN, California Pacific Medical Center, San Francisco, CA; Akio Iwanaga, PhD, Sacramento, CA; Ted Heine, MBA, ALSA, Waverly, IA; and Harry Cuddy, BA, ALSA, Los Altos, CA

Note. Readers can obtain 40 pages of supplementary material from the National Auxiliary Publications Service, 248 Hempstead Turnpike, West Hempstead, NY 11552. Request document no. 05511. Remit with your order, not under separate cover, in US funds only, $\$ 7.75$ for photocopies or $\$ 4.00$ for microfiche. Outside of the United States and Canada, add postage of $\$ 4.50$ for the first 20 pages and $\$ 1.00$ for each 10 pages of material thereafter, or $\$ 1.75$ for the first microfiche and $\$ 0.50$ for each microfiche thereafter. Institutions and organizations may order by purchase order; however, there is a $\$ 15.00$ invoicing charge, plus any applicable postage, on all orders filled before payment.

\section{References}

(Strength of evidence is indicated for references used to formulate recommendations.)

1. Quality Standards Subcommittee of the American Academy of Neurology. Practice advisory on the treatment of amyotrophic lateral sclerosis with riluzole. Neurology 1997;49:657659. (Class I)

2. Subcommittee on Motor Neuron Diseases/Amyotrophic Lateral Sclerosis of the World Federation of Neurology Research Group on Neuromuscular Diseases, El Escorial "Clinical Limits of Amyotrophic Lateral Sclerosis" Workshop Contributors. El Escorial World Federation of Neurology criteria for the diagnosis of amyotrophic lateral sclerosis. J Neurol Sci 1994;124(suppl):96-107. (Class III)

3. Lind SE, Good MD, Seidel S, Csordas T, Good BJ. Telling the diagnosis in cancer. J Clin Oncol 1989;7:583-589. (Class III)

4. Damian D, Tattersall MHN. Letters to patients: improving communication in cancer care. Lancet 1991;338:923-925. (Class I)

5. Tattersall MHN, Butow PN, Griffin A, Dunn SM. The takehome message: patients prefer consultation audiotapes to summary letters. J Clin Oncol 1994;12:1305-1311. (Class I)

6. Doyle D. Breaking bad news. J R Soc Med 1996;89:590-591. (Class III)

7. Okamura H, Uchitomi Y, Sasako M, Eguchi K, Kakizoe T. Guidelines for telling the truth to cancer patients. J Clin Oncol 1998;2:1-4. (Class III)

8. Post SG, Whitehouse PJ. Fairhill guidelines on the ethics of the care of people with Alzheimer's disease: a clinical summary. Center for Biomedical Ethics, Case Western Reserve University and the Alzheimer's Association. J Am Geriatr Soc 1995;43:1423-1429. (Class III)

9. Davies E, Hopkins A. Good practice in the management of adults with malignant cerebral glioma: clinical guidelines. Working group. Br J Neurosurg 1997;11:318-330. (Class III)

10. Girgis A, Sanson-Fisher RW. Breaking bad news: consensus guidelines for medical practitioners. J Clin Oncol 1995;13: 2449-2456. (Class III)

11. Ptacek JT, Eberhardt TL. Breaking bad news: a review of the literature. JAMA 1996;276:496-502. (Class III)

12. Blackhall LJ, Murphy ST, Frank G, Michel V, Azen S. Ethnicity and attitudes toward patient autonomy. JAMA 1995; 274:820-825. (Class III)

13. Charchaflie RJ, Fernandez LB, Perec CJ, Gonzalez E, Marzi A. Functional studies of the parotid and pancreas glands in amyotrophic lateral sclerosis. J Neurol Neurosurg Psychiatry 1974;37:863-867. (Class III)
14. Goode RL, Smith RA. The surgical management of sialorrhea. Laryngoscope 1970;80:1078-1089. (Class III)

15. Blasco PA, Stansbury JCK. Glycopyrrolate treatment of chronic drooling. Arch Pediatr Adolesc Med 1996;150:932935. (Class III)

16. Stern LM. Preliminary study of glycopyrrolate in the management of drooling. J Paediatr Child Health 1997;33:52-54. (Class III)

17. Camp-Bruno JA, Winsberg BG, Green-Parsons AR, Abrams JP. Efficacy of benztropine therapy for drooling. Dev Med Child Neurol 1989;31:309-319. (Class I)

18. Reddihough D, Johnson H, Staples M, Hudson I, Exarchos H. Use of trihexyphenidol hydrochloride to control drooling of children with cerebral palsy. Dev Med Child Neurol 1990;32: 985-989. (Class III)

19. Brodtkorb E, Wyzocka-Bakowska MM, Lillevold PE, Sandvik L, Saunte C, Hestnes A. Transdermal scopolamine in drooling. J Ment Def Res 1988;32:233-237. (Class I)

20. Lewis DW, Fontana C, Mehallick LK, Everett Y. Transdermal scopolamine for reductions in drooling in developmentally delayed children. Dev Med Child Neurol 1994;36:484486. (Class I)

21. Talmi YP, Finkelstein Y, Zohar Y, Laurian N. Reduction of salivary flow with scopoderm TTS. Ann Otol Rhinol Laryngol 1988;97:128-130. (Class III)

22. Dworkin JP, Nadal JC. Nonsurgical treatment of drooling in a patient with closed head injury and severe dysarthria. Dysphagia 1991;6:40-49. (Class III)

23. Newell AR, Orser R, Hunt M. The control of oral secretions in bulbar ALS/MND. J Neurol Sci 1996;139(suppl):43-44. (Class IU)

24. Bach JR. Mechanical insufflation-exsufflation: comparison of peak expiratory flows with manually assisted and unassisted coughing techniques. Chest 1993;104:1553-1562. (Class III)

5. Bach JR, Smith WH, Michaels J, et al. Airway secretion clearance by mechanical exsufflation for postpoliomyelitis ventilator assisted individuals. Arch Phys Med Rehabil 1993; 74:170-177. (Class III)

26. Robinson ACR, Khoury GG, Robinson PM. Role of irradiation in the suppression of parotid secretions. J Laryngol Otol 1989;103:594-595. (Class III)

27. Janzen VD, Rae R, Hudson AJ. Otolaryngologic manifestations of amyotrophic lateral sclerosis. J Otolaryngol 1988;17: 41-42. (Class III)

28. Poeck K. Pathologisches lachen und weinen bei bulbrer myatrophischer lateralsklerose. Deutsche Med Wochenschr 1996;94:310-314. (Class III)

29. Schiffer RB, Cash J, Herndon RM. Treatment of emotional lability with low-dosage tricyclic antidepressants. Psychosomatics 1983;24:1094-1096. (Class III)

30. Caroscio JT, Cohen JA, Gudesblatt M. Amitriptyline in amyotrophic lateral sclerosis. N Engl J Med 1985;313:1478. Letter. (Class III)

31. Gallagher JP. Pathologic laughter and crying in ALS: a search for their origin. Acta Neurol Scand 1989;80:114-117. (Class III)

32. Schiffer RB, Herndon RM, Rudick RA. Treatment of pathologic laughing and weeping with amitriptyline. N Engl J Med 1985;312:1480-1482. (Class I)

33. Iannaccone S, Ferini-Strambi L. Pharmacologic treatment of emotional lability. Clin Neuropharmacol 1996;19:532-535. (Class III)

34. Kasarskis EJ, Berryman S, Vanderleest JG, Schneider AR, McClain CJ. The nutritional status of patients with amyotrophic lateral sclerosis: relation to the proximity of death. Am J Clin Nutr 1996;63:130-137. (Class III)

35. Slowie LA, Paige MS, Antel JP. Nutritional considerations in the management of patients with amyotrophic lateral sclerosis (ALS). J Am Diet Assoc 1983;83:44-47. (Class III)

36. Martin BJ, Corlew MM, Wood H, et al. The association of swallowing dysfunction and aspiration pneumonia. Dysphagia 1994;9:1-6. (Class II)

37. Schmidt J, Holas M, Halvorson K, Reding M. Videofluoroscopic evidence of aspiration predicts pneumonia and death but not dehydration following stroke. Dysphagia 1994;9:711. (Class III)

38. Wilcox F, Liss JM, Siegel GM. Interjudge agreement in 
videofluoroscopic studies of swallowing. J Speech Hear Res 1996;39:144-152. (Class III)

39. Mathus-Vliegen LMH, Louwerse LS, Merkus MP, Tytgat GNS, Vianney de Jong JMP. Percutaneous endoscopic gastrostomy in patients with amyotrophic lateral sclerosis and impaired pulmonary function. Gastrointest Endosc 1994;40: 463-469. (Class II)

40. Mazzini L, Corra T, Zaccala M, Mora G, Del Piano M, Galante M. Percutaneous endoscopic gastrostomy and enteral nutrition in amyotrophic lateral sclerosis. Neurology 1995; 242:695-698. (Class II)

41. Llaneza PP, Menendez AM, Roberts R, Dunn GD. Percutaneous endoscopic gastrostomy: clinical experience and followup. South Med J 1988;81:321-324. (Class III)

42. Mighell AJ, Carton ATM, Boobis LH, Stassen LFA. Acceptance and perception of percutaneous endoscopic gastrostomy by patients with upper digestive tract cancer. Br J Oral Maxillofac Surg 1995;33:19-22. (Class III)

43. Park RH, Allison MC, Lang J, et al. Randomised comparison of percutaneous endoscopic gastrostomy and nasogastric tube feeding in patients with persisting neurological dysphagia. BMJ 1992;304:1406-1409. (Class I)

44. Akpunonu BE, Mutgi AB, Roberts C, Khuder SA, Federman DJ, Lee L. Modified barium swallow does not affect how often PEGs are placed after stroke. J Clin Gastroenterol 1997;24:74-78. (Class III)

45. Leighton SEJ, Burton MJ, Lund WS, Cochrane GM. Swallowing in motor neuron disease. J R Soc Med 1994;87:801805. (Class III)

46. The role of percutaneous endoscopic gastrostomy in enteral feeding. Guidelines for clinical application. Gastrointest Endosc 1988;34(suppl 3):35S-36S. (Class III)

47. Sherman MS, Paz HL. Review of respiratory care of the patient with amyotrophic lateral sclerosis. Respiration 1994; 61:61-67. (Class III)

48. Stambler N, Charatan M, Cedarbaum JM. Prognostic indicators of survival in ALS. ALS CNTF Treatment Study Group. Neurology 1998;50:66-72. (Class I)

49. Nordt SP, Clark RF. Midazolam: a review of therapeutic u and toxicity. J Emerg Med 1997;15:357-365. (Class III

50. DiSario JA, Foutch PG, Sanowski RA. Poor results with percutaneous endoscopic jejunostomy. Gastrointest Endosc 1990;36:257-260. (Class III)

51. Hassett JM, Sunby C, Flint LM. No elimination of aspiration pneumonia in neurologically disabled patients with feeding gastrostomy. Surg Gynecol Obstet 1988;167:383-388. (Class II)

52. Jarnagin WR, Duh Q, Mulvihill SJ, Ridge JA, Schrock TR, Way LW. The efficacy and limitations of percutaneous endoscopic gastrostomy. Arch Surg 1992;127:261-264.(Class III)

53. Kadakia SC, Sullivan HO, Starnes E. Percutaneous endoscopic gastrostomy or jejunostomy and the incidence of aspiration in 79 patients. Am J Surg 1992;164:114-118. (Class III)

54. Patel PH, Thomas E. Risk factors for pneumonia after percutaneous endoscopic gastrostomy. Clin Gastroenterol 1990;12: 389-392. (Class III)

55. Cogen R, Weinryb J. Aspiration pneumonia in nursing home patients fed via gastrostomy tubes. Am J Gastroenterol 1989; 84:1509-1512. (Class III)

56. Light VL, Slezak FA, Porter JA, Gerson LW, McCord G. Predictive factors for early mortality after percutaneous endoscopic gastrostomy. Gastrointest Endosc 1995;42:330-335. (Class III)

57. Sartori S, Trevisani L, Tassinari D, et al. Prevention of aspiration pneumonia during long-term feeding by percutaneous endoscopic gastrostomy: might cisapride play any role? An open pilot study. Support Care Cancer 1994;2:188-190. (Class III)

58. Carter GT, Johnson ER, Bonekat HW, Lieberman JS. Laryngeal diversion in the treatment of intractable aspiration in motor neuron disease. Arch Phys Med Rehabil 1992;73:680682. (Class III)

59. Hawthorne M, Gray R, Cottam C. Conservative laryngectomy-an effective treatment for severe aspiration in motor neuron disease. J Laryngol Otol 1987;101:283-285. (Class III)

60. MacDougall G, Wilson JA, Pryde A, Grant R. Analysis of the pharyngoesophageal pressure profile in amyotrophic lateral sclerosis. Otolaryngol Head Neck Surg 1995;112:258-261. (Class II)

61. Aboussouan LS, Khan SU, Meeker DP, Stelmach K, Mitsumoto H. Effect of noninvasive positive-pressure ventilation on survival in amyotrophic lateral sclerosis. Ann Intern Med 1997; 127:450-453. (Class II)

62. Barbè F, Quera-Salva MA, de Lattre J, Gajoddos P, Agustii AGN. Long-term effects of nasal intermittent positivepressure ventilation on pulmonary function and sleep architecture in patients with neuromuscular diseases. Chest 1996; 110:1179-1183. (Class II)

63. Schlamp V, Karg O, Abel A, Schlotter B, Wasner M, Borasio GD. Nicht-invasive intermittierende Selbstbeatmung (ISB) als Palliativmaßnahme bei amyotropher Lateralsklerose [Non-invasive intermittent home mechanical ventilation as a palliative treatment in amyotrophic lateral sclerosis]. Nervenarzt 1998;69:1074-1082. (Class III)

64. Poponick JM, Jacobs I, Supiski G, DiMarco AF. Effect of upper respiratory tract infection in patients with neuromuscular disease. Am J Respir Crit Care Med 1997;156:659-664. (Class III)

65. Fallat RJ, Jewitt B, Bass M, Kamm B, Norris FH Jr. Spirometry in amyotrophic lateral sclerosis. Arch Neurol 1979;36: 74-80. (Class III)

66. Rochester DF, Esau SA. Assessment of ventilatory function in patients with neuromuscular disease. Clin Chest Med 1994;14:751-763. (Class III)

67. Vitacca M, Clini E, Facchetti D, et al. Breathing pattern and respiratory mechanics in patients with amyotrophic lateral sclerosis. Eur Respir J 1997;10:1614-1621. (Class III)

68. Schiffman PL, Belsh JM. Pulmonary function at diagnosis of amyotrophic lateral sclerosis. Rate of deterioration. Chest 1993,103:508-513. (Class III)

Griggs RC, Donohoe KM, Utell MJ, Goldblatt D, Moxley RT. Evaluation of pulmonary function in neuromuscular disease. Arch Neurol 1981;38:9-12. (Class III)

Kaplan LM, Hollander D. Respiratory dysfunction in amyotrophic lateral sclerosis. Clin Chest Med 1994;15:675-681. (Class III)

71. Cazzolli PA, Oppenheimer EA. Home mechanical ventilation for amyotrophic lateral sclerosis: nasal compared to tracheostomy-intermittent positive pressure ventilation. J Neurol Sci 1996;139(suppl):123-128. (Class III)

72. Bach JR. Amyotrophic lateral sclerosis: predictors for prolongation of life by noninvasive respiratory aids. Arch Phys Med Rehabil 1995;76:828-832. (Class III)

73. Howard RS, Wiles CM, Loh L. Respiratory complications and their management in motor neuron disease. Brain 1989;112: 1155-1170. (Class III)

74. Piper AJ, Sullivan CE. Effects of long-term nocturnal nasal ventilation on spontaneous breathing during sleep in neuromuscular and chest wall disorders. Eur Respir J 1996;9: 1515-1522. (Class II)

75. Pinto AC, Evangelista T, Carvalho M, Alves MA, Sales Luis ML. Respiratory assistance with a non-invasive ventilator (Bipap) in MND/ALS patients: survival rates in controlled trials. J Neurol Sci 1995;129(suppl):19-26. (Class II)

76. Goldblatt D, Greenlaw J. Starting and stopping the ventilator for patients with amyotrophic lateral sclerosis. Neurol Clin 1989;7:789-806. (Class III)

77. Oppenheimer EA. Decision-making in the respiratory care of amyotrophic lateral sclerosis: should home mechanical ventilation be used? Palliat Med 1993;5(suppl 2):49-64. (Class III)

78. Bach JR. Amyotrophic lateral sclerosis. Communication status and survival with ventilatory support. Am J Phys Med Rehabil 1993;72:343-349. (Class III)

79. McDonald ER, Hillel A, Wiedenfeld SA. Evaluation of the psychological status of ventilatory-supported patients with ALS/MND. Palliat Med 1996;10:35-41. (Class II)

80. Moss AH, Oppenheimer EA, Casey P, et al. Patients with amyotrophic lateral sclerosis receiving long-term mechanical ventilation: advance care planning and outcomes. Chest 1996;110:249-255. (Class III)

81. Moss AH, Casey P, Stocking CB, Roos RP, Brooks BR, Siegler M. Home ventilation for amyotrophic lateral sclerosis 
patients: outcomes, costs, and patient, family and physician attitudes. Neurology 1993;43:438-443. (Class III)

82. Bach JR, Campagnolo DI, Hoeman S. Life satisfaction of individuals with Duchenne muscular dystrophy using longterm mechanical ventilatory support. Am J Phys Med Rehabil 1991;70:129-135. (Class II)

83. American Academy of Neurology Ethics and Humanities Subcommittee. Position statement: certain aspects of the care and management of profoundly and irreversibly paralyzed patients with retained consciousness and cognition. Neurology 1993;43:222-223. (Class III)

84. Bernat JL, Cranford RE, Kittredge FI Jr, Rosenberg RN. Competent patients with advanced states of permanent paralysis have the right to forgo life-sustaining therapy. Neurology 1993;43:224-225. (Class III)

85. Gilligan T, Raffin TA. Withdrawing life support: extubation and prolonged terminal weans are inappropriate. Crit Care Med 1996;24:352-353. (Class III)

86. The American Academy of Neurology Ethics and Humanities Subcommittee. Palliative care in neurology. Neurology 1996; 46:870-872. (Class III)

87. Nelson WA, Bernat JL. Decisions to withhold or terminate treatment. Neurol Clin 1989;7:759-773. (Class III)

88. Wilson WC, Smedira NG, Fink C, McDowell JA, Luce JM. Ordering and administration of sedatives and analgesics during the withholding and withdrawal of life support from critically ill patients. JAMA 1992;267:949-953. (Class III)

89. Truog RD, Burns JP. To breathe or not to breathe. J Clin Ethics 1994;5:39-41. (Class III)

90. Campbell ML. Case studies in terminal weaning from mechanical ventilation. Am J Crit Care 1993;2:354-358. (Class III)

91. Campbell ML, Nelson LJ, Hoyt JW. Health Care Ethics Forum 94: perspectives on withholding and withdrawal of lifesupport. AACN Clin Issues 1994;5:353-359. (Class III)

92. Roelfs RA, Mulder DW. The initial patient interview. In: Mulder DW, ed. The diagnosis and treatment of amyotrophic lateral sclerosis. Boston: Houghton Mifflin Professional Publishers, 1980:129-140. (Class III)

93. Newrick PG, Langton-Hewer R. Pain in motor neuron disease. J Neurol Neurosurg Psychiatry 1985;48:838-840. (Class III)

94. O’Brien T, Kelly M, Sunders C. Motor neuron disease: a hospice perspective. BMJ 1992;304:471-473. (Class III)

95. Oliver D. Ethical issues in palliative care-an overview. Palliat Med 1993;7(suppl 2):15-20. (Class III)

96. Saunders C, Walsh TE, Smith M. Hospice care in motor neuron disease. In: Saunders C, Summers DH, Teller N, eds. Hospice: the living idea. London: Edward Arnold, 1981:126147. (Class III)

97. World Health Organization. Cancer pain relief. Report of the WHO expert committee. Technical report series 804. Geneva: World Health Organization, 1990. (Class III)

98. Bruera E, de Stoutz N, Velasco-Leiva A, Schoeller T, Hanson J. Effects of oxygen on dyspnoea in hypoxaemic terminal cancer patients. Lancet 1993;342:13-14. (Class I)
99. Booth S, Kelly MJ, Cox NP, Adams L, Guz A. Does oxygen help dyspnea in patients with cancer? Am J Respir Crit Care Med 1996;153:1515-1518. (Class III)

100. McIver B, Walsh D, Nelson K. The use of chlorpromazine for symptom control in dying cancer patients. J Pain Symptom Manage 1994;9:341-345. (Class III)

101. Filshie J, Penn K, Ashley S, Davis CL. Acupuncture for the relief of cancer-related breathlessness. Palliat Med 1996;10: 145-150. (Class III)

102. Kane RL, Wales J, Bernstein L, Leibowitz A, Kaplan S. A randomized controlled trial of hospice care. Lancet 1984;1: 890-894. (Class I)

103. Wallston KA, Burger C, Smith RA, Baugher RJ. Comparing the quality of death for hospice and non-hospice cancer patients. Med Care 1988;26:177-182. (Class II)

104. Teno JM, Lynn J, Connors AF Jr, et al. The illusion of end-of-life resource savings with advance directives. SUPPORT Investigators. Study to understand prognoses and preferences for outcomes and risks of treatment. J Am Geriatr Soc 1997;45:513-518. (Class I)

105. Schneiderman LJ, Pearlman RA, Kaplan RM, Anderson JP, Rosenberg EM. Relationship of general advance directives instructions to specific life-sustaining treatment preferences in patients with serious illness. Arch Intern Med 1992;152: 2114-2122. (Class II)

106. SUPPORT principal investigators. A controlled trial to improve care for seriously ill hospitalized patients-the study to understand prognoses and preferences for outcomes and risks of treatment (SUPPORT). JAMA 1995;274:1591-1598. (Class I, II)

107. Reilly BM, Wagner M, Magnussen CR, Ross JH, Papa L, Ash J. Promoting inpatient directives about life-sustaining treatments in a community hospital. Results of a 3-year timeseries intervention trial. Arch Intern Med 1995;155:23172323. (Class II)

108. Mower WR, Baraff LJ. Advance directives-effect of type of directive on physicians' therapeutic decisions. Arch Intern Med 1993;153:375-381. (Class III)

109. Davidson KW, Hackler C, Caradine DR, McCord RS. Physicians' attitudes on advance directives. JAMA 1989;262:24152419. (Class III)

110. Johnston SC, Pfeifer MP, McNutt R. The discussion about advance directives. Patient and physician opinions regarding when and how it should be conducted. End of Life Study Group. Arch Intern Med 1995;155:1025-1030. (Class III)

111. Silverstein MD, Stocking CB, Antel JP. Amyotrophic lateral sclerosis and life sustaining therapy: a patients' desires for information, participation in decision making and life sustaining therapy. Mayo Clin Proc 1991;66:906-913. (Class III)

112. Voltz R, Borasio G. Palliative therapy in the terminal stage of neurological disease. Neurology 1997;244(suppl 4):S2-S10. (Class III) 


\section{Neurology}

Practice parameter: The care of the patient with amyotrophic lateral sclerosis (an evidence-based review) [RETIRED]: Report of the Quality Standards Subcommittee of the American Academy of Neurology

R.G. Miller, J.A. Rosenberg, D.F. Gelinas, et al.

Neurology 1999;52;1311

DOI 10.1212/WNL.52.7.1311

This information is current as of April 1, 1999

\section{Updated Information \&} Services

Citations

Permissions \& Licensing

Reprints including high resolution figures, can be found at: http://n.neurology.org/content/52/7/1311.full

This article has been cited by 41 HighWire-hosted articles: http://n.neurology.org/content/52/7/1311.full\#\#otherarticles

Information about reproducing this article in parts (figures,tables) or in its entirety can be found online at:

http://www.neurology.org/about/about_the_journal\#permissions

Information about ordering reprints can be found online:

http://n.neurology.org/subscribers/advertise

Neurology ${ }^{\circledR}$ is the official journal of the American Academy of Neurology. Published continuously since 1951, it is now a weekly with 48 issues per year. Copyright . All rights reserved. Print ISSN: 0028-3878.

Online ISSN: 1526-632X.

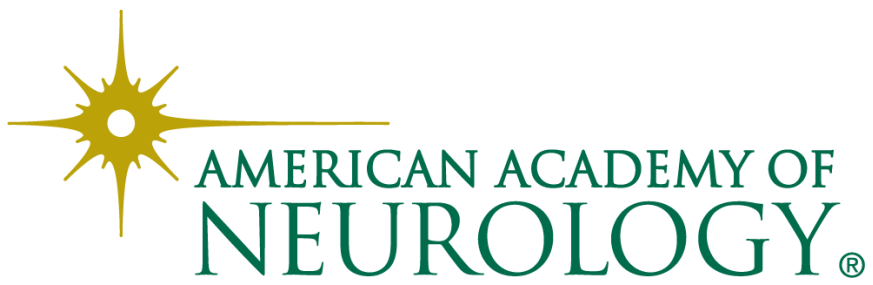

